\title{
(5) MOVIMENTO

\section{POSIÇÕES E TOMADAS DE POSIÇÕES NA CONSTITUCIONALIZAÇÃO DO DIREITO AO ESPORTE NO BRASIL}

\author{
STANCES AND STANCE-TAKING IN THE CONSTITUTIONALIZATION OF THE \\ RIGHT TO SPORT IN BRAZIL
}
POSICIONES Y TOMA DE POSTURA EN LA CONSTITUCIONALIZACIÓN DEL DERECHO AL DEPORTE EN BRASIL

Felipe Canan*, Fernando Augusto Starepravo**, Juliano de Souza**

\author{
Felipe Canan", Fernando Augusto Starepravo*, Jullano de Souza
}

Palavras chave:

Políticas públicas. Direito internacional. Sociologia.
Resumo: Buscamos identificar fatores histórico-sociológicos determinantes para que o esporte adquirisse o caráter de direito constitucional no Brasil. Revisitamos a história do período pré-constituinte, analisando-a 1) à luz de pressupostos do direito internacional em sentido lato e 2) das contribuições teóricas de Pierre Bourdieu. Ainda que as demandas da comunidade esportiva nacional tenham se dado em função da liberalização da iniciativa privada, certos movimentos dentro do campo político-esportivo, sobretudo influenciados por Manoel Tubino, agente com capital cultural em muito pautado em documentos internacionais, foram fundamentais para constitucionalização do direito ao esporte.

\section{Keywords:} Public Policy. International Right. Sociology.

Palabras clave: Políticas Públicas. Derecho Internacional. Sociología.
Abstract: We seek to identify crucial historical and sociological factors that caused sport to become a constitutional right in Brazil. We revisit the history of the pre-constitutional period, analyzing it in the light of [1] basis of international law in the broad sense and [2] Pierre Bourdieu's contributions. Although the demands of Brazil's sports community have been a result of liberalization of private initiative, some movements within the politicalsports field, mainly influenced by Manoel Tubino - an agent with cultural capital based heavily on international documents - were crucial for the constitutionalization of the right to sport.

Resumen: Buscamos identificar los factores históricos y sociológicos determinantes para que el deporte adquiriese el carácter de derecho constitucional en Brasil. Examinamos la historia del periodo preconstitucional y la analizamos [1] a la luz de supuestos del derecho internacional en el sentido amplio y [2] de las aportaciones teóricas de Pierre Bourdieu. Aunque las demandas de la comunidad deportiva nacional han resultado de la liberalización de la iniciativa privada, algunos movimientos dentro del campo políticodeportivo, influenciados principalmente por Manoel Tubino, agente con capital cultural en gran medida guiado por documentos internacionales, fueron fundamentales para la constitucionalización del derecho al deporte.
*Universidade Estadual do Oeste do Paraná. Marechal Cândido Rondon, PR, Brasil.

E-mail: felipe.canan@gmail.com

**Universidade Estadual de Maringá. Maringá, PR, Brasil.

E-mail: fernando.starepravo@hotmail.com; julianoedf@yahoo.com.br

Recebido em: 20-10-2016 Aprovado em: 08-05-2017 (c) (i) () Licence 


\section{INTRODUÇÃOO}

Qualquer objeto, para ser demandante de políticas públicas, precisa, antes, ser compreendido como necessidade das pessoas e garantido enquanto tal pela via legal. Os direitos fundamentais normalmente são fruto de disputas dentro do campo sociopolítico e passam a ser assim considerados a partir de reivindicações e conquistas de determinados grupos ou da coletividade frente ao Estado.

A partir de tais considerações, adotamos como temática a constitucionalização do esporte no Brasil, traçando como objetivo identificar quais fatores foram determinantes para que o esporte adquirisse o caráter de direto constitucional no país. Para tanto, desenvolvemos um ensaio bibliográfico-documental pautado em dois referenciais teóricos que, para discussão do nosso objeto, entendemos complementares: 1) a sociologia reflexiva de Pierre Bourdieu, mais especificamente suas categorias praxiológicas de campo, habitus e capitais, somadas a algumas de suas proposições a respeito do Estado; e 2) os pressupostos do que denominamos "direito internacional em sentido lato", que abrangeria os direitos internacional público, transnacional e comparado.

O elemento motivador que nos leva a buscar subsídios nesses referenciais é a potencialidade que abrem para analisarmos a centralidade da figura de Manoel José Gomes Tubino na constitucionalização do direito ao esporte no Brasil. Tal como teremos a oportunidade de aprofundar, Tubino foi um agente que vivenciou os campos sociais militar, acadêmico, esportivo e político, nacional e internacionalmente, e parece ter conseguido gerar algumas interconexões entre eles, de forma a influenciar o caráter do texto constitucional sobre esporte e o próprio reordenamento do campo político-esportivo ${ }^{1}$ no período pré-constitucional. Partimos, assim, da hipótese de que tal agente foi o principal responsável pela constitucionalização do direito ao esporte no Brasil.

Tubino, como demonstraremos, constrói seus posicionamentos acadêmicos e políticoideológicos sobre a relação entre Estado e esporte, no período da Abertura Política (19851988), adotando como base a literatura, legislação e documentos internacionais, o que nos leva a acreditar na importância de adotar processos do direito internacional em sentido lato como instrumento teórico de análise.

Em busca de compreender a participação do agente no campo, buscamos revisitar legislação e documentos, nacionais e internacionais e a literatura citada por ele, o que justifica o caráter bibliográfico-documental de nosso ensaio. Ao mesmo tempo, Souza e Marchi Júnior (2010, p. 294), ao referirem-se ao argumento metodológico que anima o projeto sociológico de Bourdieu, esclarecem que esse autor:

[...] procura instaurar uma perspectiva de apreensão do mundo social onde 0 sociólogo não renuncia ao seu privilégio epistemológico de explicação dos fatos sociais, mas também não desconsidera o valor das experiências dos agentes num universo empiricamente delimitado.

Neste texto, não perdemos de vista essa dupla perspectiva e, em nosso esforço de compreensão da problemática exposta, nos aprouve recortar empiricamente o período estabelecido entre 1985 e 1988, por entender que o primeiro corresponde à chegada de Tubino

1 Utilizamos o termo "campo" sob a perspectiva de Pierre Bourdieu, que será discutida adiante no texto. Já o termo político-esportivo foi adotado porque acreditamos que diga respeito ao espaço social (campo) de inter-relações entre o Estado e o esporte, ou seja, às formas de intervenção, mais ou menos institucionalizadas e diretas, do Estado sobre o esporte. 
à presidência do Conselho Nacional de Desportos (CND), órgão estatal diretivo do esporte naquele período, e da então instituída "Comissão de Reformulação do Desporto Nacional" (CRDN) (TUBINO, 1988), possivelmente os fatos mais marcantes para a nova roupagem do campo político-esportivo nacional; e o segundo diz respeito ao ano em que foi promulgada a atual Constituição da República Federativa do Brasil (CF).

\section{PRESSUPOSTOS TEÓRICOS - DIREITO INTERNACIONAL EM SENTIDO LATO E SOCIOLOGIA REFLEXIVA DE PIERRE BOURDIEU}

Denominamos aqui como "direito internacional em sentido lato" o ramo do direito que trata da relação existente entre o corpus jurídico-normativo de diferentes países, de organizações intergovernamentais e do ordenamento não estatal, este proveniente de fontes privadas, na forma, sobretudo, de instituições transnacionais. Para tanto, precisamos recorrer ao modus operandi de três disciplinas do direto que, embora próximas e, muitas vezes, complementares, são tratadas em separado: direito comparado, direito internacional público e direito transnacional. Sendo nosso objeto o processo constituinte, precisamos levar em consideração as influências internacionais exercidas, pois que a criação de uma nova lei comumente pauta-se em um processo de inspiração em outros ordenamentos, não surgindo, portanto, do zero (TAVARES, 1987).

Uma rápida conceituação do direito comparado nos esclarece que trata, como o próprio nome já indica, da comparação do ordenamento jurídico de um país com o de outro, podendo gerar inovação ou imitação no ordenamento daquele que compara. Como coloca Tavares (1987), o direito brasileiro é pródigo em empréstimos (imitações) de outros ordenamentos jurídicos, a tal ponto de chegar a ser considerado como uma síntese de direitos europeus, ainda que, mais ou menos ajustados à realidade nacional, em decorrência de um processo de "aculturação jurídica".

Já o direito transnacional trata de ordenamentos jurídicos provenientes de entidades privadas transnacionais - federações esportivas, por exemplo -, que se afiguram como instituições destinadas a regulamentar um objeto imaterial que se manifesta nos diversos territórios e acabam gerando confluências entre normas estatais e normas não estatais (FARIA, 2015).

Esse processo de relação entre diferentes sistemas jurídicos (chamado de internormatividade) utiliza-se de técnicas de intercâmbio, das quais se destacam o próprio direito comparado e a figura dos chamados "intermediários", que se traduzem por agentes ou instituições públicas ou privadas com atuação nacional ou regional e ligação com instituições inter/transnacionais e que podem, devido à posição/influência que ocupam, oferecer legitimidade e "portas de entrada" para a legislação internacional, a traduzindo, adaptando e contextualizando à realidade local, a partir de diagnósticos feitos sobre a realidade nacional (FARIA, 2015).

O direito internacional público, por sua vez, trata da relação direta entre os sujeitos de direito internacional público, como Estado e organizações intergovernamentais - Organização das Nações Unidas (ONU), por exemplo -, quando se associam para discutir e acordar a respeito de determinados temas de interesse comum. As decisões proferidas por essas organizações podem ter efeito vinculante, ou seja, de cumprimento obrigatório, ou podem ser meramente declaratórias ou recomendatórias, de caráter de cumprimento discricionário por 
parte dos Estados (MAZZUOLI, 2011). Acreditamos que a sistemática de aceitação estatal das normas do direito transnacional (utilização de intermediários, sobretudo) possa subsidiar a compreensão de como o Estado responde às decisões não vinculantes das organizações intergovernamentais (estas pertinentes ao direito internacional público).

Ao mesmo tempo em que as teorias do direito internacional em sentido lato nos são caras para compreender a constitucionalização do direito ao esporte no Brasil, temos clareza de que tal fenômeno não pode ser compreendido somente a partir delas, mas, também, dos acontecimentos sociais, mais ou menos institucionalizados, ocorridos naquele momento. Para análise desses acontecimentos, elegemos como marco teórico os pressupostos da sociologia de Pierre Bourdieu, da qual nos interessa particularmente, além do próprio exercício de reflexão epistemológica defendido pelo autor, tanto as categorias de análise e compreensão social, "campo", "habitus" e "capital", quanto as considerações do autor sobre o Estado enquanto instituição que detém o poder simbólico para afirmar o que é certo e legítimo no mundo social (BOURDIEU, 2005; 2014).

Para levar a cabo esse exercício, consideramos inicialmente o que propõe Bourdieu (2005), quando argumenta que o ofício do pesquisador no campo das Ciências Sociais está justamente em realizar a vigilância epistemológica, isto é, em identificar os pré-construídos e os processos ocultos referentes ao senso comum e ao senso douto, sendo este último aquele discurso que se afirma científico, mas que, na realidade, é permeado por muitas ideologias e crenças. Para tanto, cabe ao pesquisador pensar relacionalmente, ou seja, considerar que o objeto social não é estanque, mas, sim, permeado por relações que, por sua vez, serão determinadas pelas (e determinantes das) disposições pessoais.

Campo, em termos bastante gerais, é um espaço de disputas sociais, dominações e conflitos influenciados, sobretudo, pelo habitus e pelos capitais dos agentes. Ou seja, é um espaço de posições relativas e relações objetivas em torno de determinado objeto e em busca do poder e/ou da conquista da violência legítima, autoridade específica ou dominação simbólica sobre outrem.

Habitus, por conseguinte, é o sistema de disposições e predileções pessoais influenciadas pelos espaços sociais (campos) em que o agente se encontra e que influenciarão esses espaços. Nas palavras do próprio Bourdieu (2003, p. 53), são "[...] estruturas estruturadas predispostas a funcionar como estruturas estruturantes [...]", ou seja, qualquer que seja a mudança no campo, esta resultará em uma transformação na disposição pessoal e vice-versa. Nesses termos, esse jogo oscilante entre subjetividade (disposição pessoal) e objetividade (posição ocupada no campo) é contemplado a partir da perspectiva da cumplicidade ontológica entre habitus e campo. Por fim, capital pode ser definido como a capacidade de acumulação de conhecimentos e/ou bens materiais que o indivíduo obtém durante sua existência. Quanto maior o reconhecimento social do agente dentro do campo, sobretudo quando institucionalizado pelo Estado (concessão de diplomas, cargos de confiança, prêmios, etc.), maior o seu capital simbólico, ou seja, o seu poder de impor aos pares o que é legítimo ou não.

\section{CARACTERIZANDO O CAMPO - APONTAMENTOS HISTÓRICOS SOBRE $O$ PROCESSO CONSTITUINTE DO ESPORTE NO BRASIL}

O campo político-esportivo no contexto de Abertura Política prospectava uma série de mudanças, sobretudo no que concerne às demandas pela liberalização em relação ao Estado que 
se apresentava autoritário, por parte da iniciativa privada. No entanto, essas demandas, somadas aos problemas no campo político-esportivo nacional, identificados por Tubino no período em que assumiu a presidência do CND (1985), quais sejam, entre outros, uma legislação esportiva considerada ultrapassada; carência de estudos sobre a realidade esportiva brasileira; e falta de um conceito de esporte para o Brasil, acabaram por esbarrar em uma estrutura historicamente centralizadora e moldada por sistemas de decisão ultrapassados (TUBINO, 1988).

Em busca de alternativas para esse quadro "centralizador e ultrapassado", foi instituída em 1985 a CRDN. Contudo, por mais que a Comissão tenha contado com a participação de diferentes personalidades relacionadas ao campo esportivo nacional (ex-atletas, por exemplo), a legitimidade dessa Comissão podia ser questionada, uma vez que muitos, embora com envolvimento notório no campo esportivo, não representavam qualquer projeto político concreto para o esporte e outros haviam sido colaboradores durante a Ditadura Militar. Ou seja, de um lado, havia membros da CRDN "[...] empenhados, agora, em processar reformas no sistema esportivo, já que as práticas arbitrárias e os abusos de poder haviam-se tornado constrangedores com a abertura política [...]" (LINHALES, 1996, p. 173), e de outro, personalidades esportivas com reconhecimento social para respaldar as decisões dos primeiros.

Quanto ao Presidente da Comissão, não temos certeza sobre as razões de sua escolha. Até 0 ano de 1985, quando assumiu a Presidência da CRDN e também do CND, no campo acadêmico Tubino ostentava o título de Doutor em Educação Física pela Universidade Livre de Bruxelas, Bélgica, exercia o magistério e cargos de direção em diferentes Instituições de Ensino Superior (IES), era conselheiro da Associação Internacional das Escolas Superiores de Educação Física (AIESEP) e despontava nacional e internacionalmente pelas várias publicações. Em 1984, iniciou um doutorado em Educação na Universidade Federal do Rio de Janeiro, a partir de quando começou a dedicar-se mais ao estudo do esporte e suas relações com a educação e o Estado. No campo esportivo, Tubino atuou, sobretudo, como atleta de caratê e preparador físico de voleibol, inclusive em nível de seleção brasileira. No campo militar, graduou-se Oficial pelo curso de Ciências Navais da Escola Naval do Rio de Janeiro, além de ter sua graduação em Educação Física sob os auspícios militares da Escola de Educação Física do Exército. No campo político, não foram encontrados indícios de alguma trajetória para além dos cargos de direção dentro das IES (TUBINO, 2009; FALA..., 1985; CONSELHO FEDERAL DE EDUCAÇÃO FÍSICA, 2009; BRASIL, 2015). A escolha de Tubino para presidir o CND e a CRDN, assim, pode ter se dado pela sua inserção no campo acadêmico, esportivo ou militar ou pelo somatório de todos, além de possíveis relações políticas preexistentes².

De qualquer maneira, tendo como premissa os pressupostos de Bourdieu $(2005 ; 2014)$ sobre o Estado e o uso simbólico de comissões de especialistas, obtemos subsídios para compreender que a CRDN parece ter sido criada a fim de representar simbolicamente uma preocupação estatal com um problema emergente e para ele apresentar soluções, mesmo que, na prática, o Estado talvez não estivesse efetivamente tão comprometido em resolver esses

2 Tubino convivia com pessoas inseridas no campo político-esportivo durante o Regime Militar, tais como Lamartine Pereira da Costa e Márcio Braga. Costa foi "veterano" de Tubino em ambas as graduações e com o qual lecionou junto e obteve a livre-docência na mesma instituição e ano, entre outras possíveis relações (TUBINO, 2009; COSTA, 2016). No campo político-esportivo, Costa foi coordenador do Diagnóstico de Educação Física/Desportos de 1971 e do Movimento Esporte para Todos no Brasil e convidado especial do Ciclo de Debates Panorama do Esporte Brasileiro organizado pela Comissão de Esporte e Turismo da Câmara dos Deputados em 1983, mas não encontramos indícios de que Tubino tenha participado de qualquer destas ações. Braga foi presidente dos citados Comissão de Esporte e Turismo e Ciclo de Debates e, segundo Rezende (1986), teria indicado Tubino ao então Ministro da Educação Marco Maciel para presidência do CND e CRDN. Maciel, por sua vez, teria justificado a nomeação de Tubino aos cargos por ser um agente com conhecimento técnico e sem ligações empresariais ou clubísticas (FALA..., 1985). 
problemas, e ainda que membros da Comissão talvez pudessem estar. Por Ihes faltar força executiva, sua ação perpassava exclusivamente o caráter técnico e simbólico.

Castellani Filho (1985), tecendo uma análise crítica sobre a CRDN já no mesmo ano da instituição desta, alertava que a democracia que se instaurava no próprio transcorrer da Ditadura Militar era, na realidade, um "acordo entre elites" e que a constituição de comissões para estudos e proposições, tal e qual a CRDN na área do esporte, consistia em uma estratégia de antecipação do Estado para desmobilização de classes populares. Sendo as propostas de mudança provenientes de iniciativas governamentais, não encontrariam organização na sociedade para colocá-las em prática de maneira efetiva.

Os resultados da CRDN, legítimos ou não, apontaram para a necessidade de revisão de várias questões, muitas das quais semelhantes ao que já vinha apontando Tubino em seus estudos/constatações pessoais (supracitados) e, em que pese a Comissão não ter qualquer poder executivo, sugeriu várias indicações de ações, dentre as quais, a constitucionalização do direito ao esporte, para os órgãos institucionais que figuravam à frente do esporte nacional à época, quais sejam, o CND e a Secretaria de Educação Física e Desportos (SEED).

O fato de o próprio Tubino acumular a presidência da CRDN e do CND e, por dois curtos mandatos, a Secretaria da SEED ${ }^{3}$, apesar da incapacidade executiva da Comissão, contribuiu para que muitas indicações pudessem ser colocadas em prática. Sendo assim, estando na base da reformulação do esporte nacional, e concomitante a um esforço na modificação de suas próprias características, coube ao CND liderar o processo de constitucionalização do direito ao esporte.

A primeira ação de Tubino enquanto presidente do CND, nesse sentido, foi, acompanhando o contexto de abertura democrática pelo qual passava o país, tornar também 0 próprio CND uma estrutura mais democrática (menos autoritária, embora ainda centralizadora) (LINHALES, 1996). Para tanto, no que Tubino (1996) chama de "ação renovadora do Conselho Nacional de Desportos", foram estabelecidas algumas prioridades, nas quais se encontrava a ideia de constitucionalização do direito ao esporte no Brasil e a desburocratização e descentralização política do esporte brasileiro.

O problema é que, como aponta Linhales (1996), o processo de descentralização do CND em busca de constituir-se como uma instituição democrática e não centralizadora como outrora deu-se, sobretudo, por progressiva liberalização das confederações esportivas, o que acabou permitindo que agentes mais pautados em interesses econômico-mercadológicos ganhassem poder no campo político-esportivo nacional.

Ou seja, ao mesmo tempo em que o CND e posteriormente a CF buscaram pela concessão de autonomia à iniciativa privada, acabaram por fortalecê-la dentro do campo político-esportivo, gerando, na prática, mais atendimento a interesses particulares marcados por ideais mercadológicos, sobretudo voltados ao alto rendimento, e fortalecendo uma classe dirigente privada (feudos esportivos), e menos aos interesses que a "revisão" do esporte nacional se propunha a fazer, em termos de atendimento esportivo à população em geral. 0

3 Segundo o site do Ministério do Esporte (2017), Tubino foi Secretário da SEED entre fevereiro e março de 1987 e fevereiro e dezembro de 1989, períodos em que acumulou o cargo com a Presidência do CND. Contudo, acreditamos que o exercício do cargo de Secretário tenha pouca relevância frente a outros acontecimentos dentro do campo político-esportivo, primeiramente porque, com aponta Linhales (1996), 0 CND é que se apresentava hegemônico dentro da estrutura burocrática federal e, segundo, porque os períodos em que Tubino exerceu o cargo parecem terem sido provisórios, apenas para suprir o ínterim entre a saída de um Secretário "definitivo" e a nomeação de outro. 0 próprio Tubino não menciona o exercício de tal cargo em seu currículo Lattes (TUBINO, 2009). 
próprio Tubino (1996) reconhece o que denominou "efeito colateral" gerado por essa etapa da reorganização do esporte nacional.

Paralelamente, em busca de constitucionalizar o esporte e de redefinir o papel do Estado frente a ele por via de sua concepção enquanto direito, coube também a Tubino e ao CND intervirem, em conjunto a agentes como Álvaro Melo Filho, conselheiro do CND e mentor intelectual da proposta que seria a base para o texto constitucional sobre o esporte (AFONSO, 1986; BARROSO, 1989; TUBINO, 1996) e os constituintes Márcio Braga, um dos líderes na Câmara pela democratização do esporte, ainda que, a princípio, por via da liberalização da iniciativa privada (LINHALES, 1996) e que teria indicado Tubino ao CND e CRDN (REZENDE, 1986), e Aécio Borba, autor do texto constitucional de base sobre o esporte (baseado na proposta de Álvaro Melo Filho) (BRASIL. ASSEMBLÉIA NACIONAL CONSTITUINTE, 1987) ${ }^{4}$.

Capitaneados por Tubino, os representantes do esporte travaram uma batalha em função de sua constitucionalização ${ }^{5}$, sobretudo, porque, em paralelo à Assembleia Nacional Constituinte, foi instituída uma "Comissão Provisória de Estudos Constitucionais", (SANTOS, 2011) que não previu o esporte em seu projeto-modelo apresentado em 1986. Mesmo tal projeto tendo sido refutado de antemão, acabou influenciando o campo político-esportivo, despertando mais veementemente a reação de vários agentes que entendiam pela necessidade/oportunidade de constitucionalização do esporte (AFONSO, 1986), inclusive, principalmente, Tubino, que fora chamado por Barroso (1989) de "o batalhador" devido à sua atuação em defesa da causa. Contudo, enquanto o pleito da maioria dos agentes envolvidos dava-se em razão da liberalização da iniciativa privada (Melo Filho, Braga e Borba, por exemplo, eram também dirigentes esportivos privados), mas com manutenção dos subsídios públicos e/ou incentivos fiscais, Tubino, ainda que não se opusesse a tal demanda, defendia também a valorização do esporte enquanto direito de todos, com se pode identificar em Afonso (1986) e Barroso (1989).

Embora o início do processo constituinte tenha previsto consultas populares por via de cartas e audiências públicas, de acordo com Linhales (1996), setores mais "progressistas", por estarem mais afeitos às demandas do campo educacional da Educação Física do que do campo esportivo, acabaram não se mobilizando em função de apresentar propostas frente ao esporte. O grupo social que poderia, assim, ter reivindicado um caráter de democratização ao esporte nacional, em concorrência com os setores esportivos privados que se mobilizaram em função da autonomia para iniciativa privada, acabou não se fazendo ouvir.

Além disso, mesmo que houvesse mais demandas de grupos progressistas, como aponta Santos (2011), a análise das propostas pelos constituintes e suas equipes foi feita por amostragem aleatória que representou, no máximo, 5\% do total. A desmobilização popular buscada por aqueles que estavam no poder, denunciada por Castellani Filho (1985), ia, assim, se confirmando.

Dentro do processo constituinte em si, na Câmara dos Deputados, as propostas populares/institucionais deveriam subsidiar a Subcomissão da Educação, Cultura e Esportes, que formularia o texto constitucional sobre o esporte, e o remeteria à Comissão da Família, da Educação, Cultura e Esportes, da Ciência e Tecnologia e da Comunicação, que, por sua vez, encaminharia o texto revisado às três comissões de sistematização e ao plenário. Segundo 0

\footnotetext{
4 Anexo à ata da 34⿳a - reunião da Subcomissão da Educação, Cultura e Esportes, realizada em 25 de maio de 1987, às 15 h, íntegra do apanhamento taquigráfico, com publicação devidamente autorizada pelo Senhor Presidente da Subcomissão, constituinte Hermes Zaneti. p. 169-177. Disponível em: <http://imagem.camara.gov.br//magem/d/pdf/sup103anc24jul1987.pdf\#page=165>. Acesso em: 12 abr. 2017. 5 Barroso (1989).
} 
próprio Tubino (1996), no entanto, foi a proposta apresentada pelo próprio CND, embasada em sugestão de Álvaro Melo Filho, ratificada pela CRDN e com redação final de Aécio Borba, que, mesmo após 100 emendas que não desfiguraram sua essência, tornou-se o texto constitucional sobre 0 esporte.

Apesar de todas as contradições e mais influências do próprio Estado e do mercado do que das classes populares, o resultado foi um texto considerado avançado em termos de democratização do esporte. Como coloca Miranda (2011, p. 21), a partir da inserção no Título da "Ordem Social" na CF, o Estado, superando a perspectiva exclusiva do esporte concebido sob o paradigma do alto rendimento que imperava até então, passa a compreendê-lo como "[...] fator autônomo propiciador de melhoria de condições de existência", e, portanto, a mais do que garantir os direitos individuais de liberdade de prática e associação, assume o dever de fomentá-lo para além do sentido de destinação de recursos, considerando suas relações com os direitos sociais à educação, saúde e, sobretudo, lazer, o compreendendo como principal meio de satisfação material deste.

\section{INFLUÊNCIA INTERNACIONAL E REFLEXIVIDADE SOBRE O PROCESSO CONSTITUINTE DO DIREITO AO ESPORTE NO BRASIL}

Se as demandas por uma reforma no campo político-esportivo nacional provinham eminentemente da iniciativa privada que buscava pela autonomia em relação à centralização estatal, mas desde que as subvenções públicas fossem mantidas, o que, na realidade, demonstrava haver interesses particulares em ganhos de poder e não interesse em democratizar a prática esportiva, por que, então, o esporte chegou ao status constitucional e, além disso, de direito garantido pela CF? Apontamos alguns fatores que, mesmo que não exaustivos, compreendemos terem sido preponderantes para tal.

A constitucionalização do esporte não se deu com exclusividade no Brasil. Ao contrário, o esporte adquire o estatuto de matéria constitucional anteriormente em outros países, comumente associado à educação, saúde e qualidade de vida (MIRANDA, 2011). A constitucionalização de um direito ao esporte, contudo, ocorreu somente em 1976, em Portugal, antes mesmo de sua previsão na "Carta Internacional da Educação Física e do Esporte" da UNESCO, de 1978, documento comumente citado por Tubino como mais importante para institucionalização em nível mundial da ideia de direito ao esporte. Tanto um quanto outro teriam influenciado o texto constitucional de 1988 no Brasil (MIRANDA, 2011), demonstrando a influência do direito internacional e comparado.

Assim, ainda que a CRDN tenha sido composta por personalidades do campo esportivo e por representantes da continuidade do período da Ditadura Militar, ao mesmo tempo tinha em seu presidente um agente que circulava entre vários campos sociais (acadêmico, esportivo, militar e, a partir de então, político) e que vinha desenvolvendo estudos em literatura e documentos internacionais sobre a teoria do esporte e sua relação com o Estado em nível internacional, 0 que viria a valorizar seu capital cultural em relação aos cargos que passava a exercer.

Parece que, independentemente de que a intenção estatal fosse de legitimar uma continuidade, como poderia se esperar com base nos pressupostos de Bourdieu (2014), ou mesmo de se antecipar a movimentações populares, conforme denunciou Castellani Filho (1985), acabou ocorrendo, em certa medida, uma ruptura, ao menos teórica, na organização 
do campo político-esportivo nacional, em muito devido à figura de Tubino, com seu habitus relacionado também ao campo acadêmico, capital cultural específico e posição que acabou por ocupar dentro do campo político-esportivo.

Acreditamos que as tomadas de posição de Tubino eram mais reflexo de um habitus relacionado ao campo acadêmico do que político, esportivo ou militar ${ }^{6}$ porque verificamos que 0 agente inseria-se sobremaneira no primeiro, destacando-se neste cenário com várias publicações, muitas das quais relativas ao campo político-esportivo. A inserção no campo esportivo parecia já ter ficado para trás; a formação militar parecia não significar atuação nesta seara, muito embora possa ter sido um dos fatores responsáveis pela introdução na política; e, como já apontado, até então, não havia uma inserção política significativa.

Sendo assim, mesmo tendo em conta a relação de Tubino com a organização militar, 0 principal capital que parece tê-lo credenciado aos cargos na política nacional parece ter sido 0 cultural, o que faria sentido se reconhecermos, em conformidade com Bourdieu (2014), que 0 Estado estaria buscando legitimar suas ações frente ao esporte por via de "gurus intelectuais", para além de personalidades do campo esportivo. Tubino, assim, agregava capital cultural aos capitais político ou esportivo dos demais membros da CRDN e do próprio CND.

Se para a inserção política de Tubino isto é apenas uma suposição, em relação aos seus posicionamentos e atuação parece ser uma prerrogativa mais concreta. Levando para o campo político seu capital cultural e sua bagagem teórica, Tubino pôde influenciar diretamente na concepção a ser adotada sobre o esporte nacional e nos rumos por este tomado na esfera político-institucional. No corpo de sua obra, Tubino afirma que a revisão do esporte nacional acompanhava uma revisão do esporte em nível mundial, gerada por três fatores bastante pontuais: a difusão do movimento "Esporte para Todos" (EPT); o envolvimento da intelectualidade mundial com as discussões a respeito do esporte; e a publicação de vários documentos por parte de entidades com atuação internacional. Sem discutir a fundo cada qual, importa-nos identificar o quanto o conhecimento e a crença de Tubino na veracidade e importância deles influenciaram na revisão do esporte nacional e, consequentemente, na constitucionalização do esporte e do direito ao esporte no país.

Concorrentemente ao que pleiteava a classe dirigente privada nacional, assim, identificamos uma capacidade de Tubino de convencimento dos pares, tendo como base seu capital cultural e a utilização do direito internacional em sentido lato. Além de pautar-se em um processo de direito comparado, em muito auxiliado por Melo Filho, também estudioso das relações entre Estado e esporte, o agente valoriza a chegada e as ações, durante a década de 1970, do EPT no Brasil, que visava à popularização do esporte (TUBINO, 1996).

Surgido na Noruega em 1967 e difundido em países que adotavam o modelo políticoadministrativo do Welfare State, o EPT esbarrou no tradicionalismo do campo político-esportivo nacional, ainda restrito à visão de esporte exclusivamente enquanto alto rendimento (TUBINO, 1996; LINHALES, 1996). Sendo assim, embora Tubino apresente consciência de que o EPT ficou longe de democratizar a prática esportiva no Brasil, baseia-se nos ideais do Movimento como um dos elementos de sua concepção sobre a relação do esporte com o Estado.

Conjuntamente, Tubino agrega elementos teóricos ao seu capital cultural, naquilo que concerne à compreensão sobre esporte e à relação "Estado-esporte", embasado em intelectuais

6 Sob os pressupostos de Lahire (2005), compreendemos que, ao assumir a presidência do CND e CRDN, Tubino não apenas teve condições de atualizar sua disposição acadêmica, como a teve estimulada, pois que vislumbrou uma possibilidade de colocar em prática (disposição para agir) aquilo que estudara e em que acreditava (disposição para crer). 
internacionais que se dedicaram ao estudo teórico-filosófico e político-jurídico do esporte a partir da década de $1970^{7}$. Segundo o próprio Tubino (1988), tais intelectuais contribuíram para a consolidação de um conceito de esporte para além da ótica do alto rendimento, passando a relacioná-lo com a promoção humana e liberdade, afigurando-se em diferentes "manifestações", das quais as mais democráticas (esporte-educação e esporte-participação), ao menos, deveriam ser fomentadas pelo Estado como direito de todos.

No mesmo sentido, Tubino parece ter recebido influência ainda mais marcante de documentos internacionais, dos quais o próprio autor (TUBINO, 1988; 1996) destaca a Carta Internacional da Educação Física e do Esporte (CARTA..., 1978), que buscou afirmar o esporte enquanto fenômeno plural não apenas voltado ao alto rendimento e enquanto direito de todos. Neste sentido, indica o documento: "Todo ser humano tem o direito fundamental de acesso à educação física e ao esporte, que são essenciais para o pleno desenvolvimento da sua personalidade" (CARTA..., 1978, p. 3).

Em que pese a Carta ser proveniente de uma entidade intergovernamental (sujeito de direito internacional público, portanto), o que poderia lhe dar caráter de cumprimento obrigatório pelos países membros, foi proclamada apenas como uma diretriz para que os Estados passassem a identificar no esporte, além de um patrimônio cultural, um meio para promoção de desenvolvimento social e, portanto, direito de todos. Não apresentando natureza vinculante, precisaria encontrar intermediadores para vigorar em cada país.

No caso do Brasil, Tubino parece chamar para si essa missão, até porque, a partir do momento em que passou a cumprir importante papel político, e identificando que as recomendações dos documentos em apreço iam diretamente ao encontro dos diagnósticos feitos por ele próprio e pela CRDN sobre o campo político-esportivo nacional, buscou por adaptálas ao ordenamento jurídico local, corroborando o modus operandi do direito transnacional apresentado por Faria (2015).

Compondo a comunidade epistêmica intertransnacional devido, sobretudo, ao seu doutoramento na Bélgica, participação na AIESEP e publicações acadêmicas, que lhe conferiam capital cultural e relevância no campo acadêmico, Tubino adquiriu também um importante capital político com sua nomeação para CND e CRDN, o que lhe conferiu capital simbólico, que se apresentava necessário para torná-lo, além de uma autoridade científica, também uma autoridade política, com poder de, senão impor, ao menos influenciar sobremaneira os demais agentes envolvidos com o campo político-esportivo nacional, intermediando a adoção das prementes ideias e inovações internacionais também no ordenamento jurídico nacional, sobretudo no que concerne à constitucionalização do direito ao esporte.

\section{CONCLUSÃO}

Não podemos desconsiderar que outros fatores tenham influenciado a constitucionalização do direito ao esporte no Brasil. Tampouco restringimos a Tubino ser o único agente responsável por tal. No entanto, ao analisarmos as configurações do campo, em que prevaleciam interesses conservadores e/ou reivindicações e movimentações para que mudanças circunscrevessem-se ao fortalecimento e atendimento dos interesses da iniciativa privada, verificamos que Tubino surge como elemento central de um processo, ao menos em

7 Tubino (1988) cita neste propósito: Noronha Feio, Luis María Cazorla Prieto, José Maria Cagigal e Urbain Clayes. 
termos ideológicos, na contramão do status quo do campo, em função de uma reorganização político-esportiva pautada da democratização.

Não nos cabe entrar no mérito de saber se as movimentações do agente tinham uma intencionalidade de efetivamente modificar o contexto ou de mascarar as ações estatais voltadas aos interesses da iniciativa privada. Ao mesmo tempo, não significa que Tubino tenha desenvolvido a priori um projeto altamente planejado e estruturado de revisão teóricoinstitucional do esporte nacional. O que acreditamos ter acontecido é que seu capital cultural, na condição de uma autoridade científica sobre o assunto, mesmo que, talvez, de maneira pré-reflexiva, acabou sendo utilizado como instrumento para tal revisão. A partir de Bourdieu (2003), temos prerrogativas para entender que, na posição político-simbólica em que Tubino se encontrou após assumir a presidência do CND e da CRDN, seu habitus, enquanto estrutura estruturada fortemente dentro do campo acadêmico, pode ter funcionado como uma das estruturas estruturantes do campo político-esportivo nacional.

Ou seja, a partir de sua inserção técnico-simbólica em cargos de direção de órgãos públicos do esporte nacional, Tubino acabou por se utilizar dos instrumentos do direto internacional em sentido lato para influir na reorganização teórico-institucional do campo político-esportivo nacional, em que pesem, na prática, as ações estatais, ao que tudo indica, terem pendido mais para o lado do pleito da classe dirigente privada, gerando o efeito de fortalecimento dos "feudos esportivos".

A predominância de continuidade de ações estatais frente ao esporte de alto rendimento, no entanto, não impede de reconhecermos ter havido avanços a partir das obras acadêmicas e da atuação política de Tubino, que, mesmo de maneira introdutória, acabaram por influenciar sobremaneira para constitucionalização do esporte e do direito ao esporte, além da subsequente e contínua reorganização político-esportiva nacional, já bastante mais democrática que outrora. $\mathrm{O}$ fato deste caráter mais democratizante ter partido mais das abstrações de um agente específico baseado em pressupostos desenvolvidos em países com democracias mais consolidadas do que da própria sociedade envolvida com o campo esportivo nacional, ao menos no período constituinte, pode nos dar uma primeira pista das razões para que o suposto "direito ao esporte" não esteja sendo garantido, ao menos satisfatoriamente, até os dias atuais.

Primeiro porque dependeu mais de uma iniciativa individual do que de demandas sociais, de forma que, conforme argumentamos ao longo do texto, foi Tubino, neste caso específico, o agente central para que, também no esporte, com base no direito internacional em sentido lato, o ordenamento jurídico brasileiro importasse o direito europeu. Segundo porque a importação desse direito e de modelos e princípios em geral que podem até ter funcionado nas localidades de origem, não necessariamente implicará em sucesso quando da implantação no território importador, até porque a sociedade que ali se encontra apresenta suas próprias características e idiossincrasias, não necessariamente estando apta a receber imitações sem que, antes, as demandem e/ou se organizem para tal. 


\section{REFERÊNCIAS}

AFONSO, Alberto Jesus. Esporte quer garantir espaço na Constituição. Correio Braziliense, p. 24, 26 out. 1986.

BARROSO, Manoel Antônio. Nova Constituição coloca o esporte em seus princípios. Jornal dos Esportes, 5 out. 1988. In: PARENTE FILHO, Marcos Santos (Org.). Esporte, educação física e constituição. São Paulo: IBRASA, 1989. p. 149-155.

BOURDIEU, Pierre. Esboço de uma teoria da prática. In: ORTIZ, Renato (Org.). A sociologia de Pierre Bourdieu. São Paulo: Olho d’Água, 2003. p. 39-72.

BOURDIEU, Pierre. O poder simbólico. 8. ed. Rio de Janeiro: Bertrand Brasil, 2005.

BOURDIEU, Pierre. Sobre o Estado. São Paulo: Companhia das Letras, 2014.

BRASIL. ASSEMBLÉIA NACIONAL CONSTITUINTE. Diário da Assembléia Nacional

Constituinte. Ano I, Supl. ao n. 103, 24 jul. 1987. Disponível em: <http://imagem.camara.gov.br/ Imagem/d/pdf/sup103anc24jul1987.pdf>. Acesso em: 12 abr. 2017.

BRASIL. Câmara dos Deputados. Honraria Professor Manoel José Gomes Tubino. 2015. Disponível em: <https:/issuu.com/confefbr/docs/ivreto_honraria_prof._manoel_jose_>. Acesso em: 15 abr. 2017.

BRASIL. Ministério do Esporte. Histórico. 2017. Disponível em: <http://www.esporte.gov.br/index. php/institucional/o-ministerio/historico>. Acesso em: 12 abr. 2017.

CARTA Internacional da Educação Física e do Esporte da UNESCO. Paris, 1978. Disponível em: <http://unesdoc.unesco.org/images/0021/002164/216489por.pdf>. Acesso em: 12 abr. 2017.

CASTELLANI FILHO, Lino. A Política Esportiva no Reino do faz-de-conta. Sprint, v. 4, n. 3, p. 20-24, 1985.

CONSELHO FEDERAL DE EDUCAÇÃO FíSICA. Homenagem: Professor Tubino. Revista Educação Física, n. 31, mar. 2009. Disponível em: <http://www.confef.org.br/extra/revistaef/show. asp?id=3764>. Acesso em: 12 abr. 2017.

COSTA, Lamartine Pereira da. Currículo Lattes. 2016. Disponível em: <http://buscatextual.cnpq. br/buscatextual/visualizacv.do?id=K4721721A5> . Acesso em: 15 abr. 2017.

FALA o novo Presidente. Placar, n. 783, p. 66, 24 maio 1985.

FARIA, Tiago Silveira de. A influência do direito desportivo transnacional no ordenamento jurídico brasileiro: da reprodução de normas à aplicação direta pela jurisdição estatal. Revista de Direito Internacional, v. 12, n. 2, p. 323-340, 2015.

LAHIRE, Bernard. Patrimónios individuais de disposições: para uma sociologia à escala individual. Sociologia, Problemas e Práticas, n. 49, p. 11-42, 2005.

LINHALES, Meily Assbú. A trajetória política do esporte no Brasil: interesses envolvidos, setores excluídos. 1996. 221 f. Dissertação (Mestrado) - Faculdade de Filosofia e Ciências Humanas da Universidade Federal de Minas Gerais, Belo Horizonte, 1996.

MAZZUOLI, Valerio de Oliveira. Curso de direito internacional público. 5. ed. São Paulo: 
MIRANDA, Martinho Neves. 0 direito no desporto. 2. ed. Rio de Janeiro: Lumen Juris, 2011.

REZENDE, Marcelo. De primeira. Placar, n. 857 , p. 30, 27 out. 1986.

SANTOS, Flávia da Cruz. Procurando o lazer na constituinte: sua inclusão como direito social na Constituição de 1988. 2011. 178 f. Dissertação (Mestrado) - Faculdade de Educação Física, Universidade Estadual de Campinas, Campinas, 2011.

SOUZA, Juliano de; MARCHI JÚNIOR, Wanderley. Por uma sociologia reflexiva do esporte: considerações teórico-metodológicas a partir da obra de Pierre Bourdieu. Movimento, v. 16, n. 1, p. 293-315, jan./mar. 2010.

TAVARES, Ana Lucia de Lyra. A utilização do direito comparado pelo legislador. Revista de Ciência Política, v. 30, n. 3, p. 85-93, jul./set. 1987.

TUBINO, Manoel José Gomes (Org.). Repensando o esporte brasileiro. São Paulo: IBRASA, 1988.

TUBINO, Manoel José Gomes. Currículo Lattes. 2009. Disponível em: <http://buscatextual.cnpq. br/buscatextual/visualizacv.do?id=K4728286H2>. Acesso em: 15 abr. 2017.

TUBINO, Manoel José Gomes. 0 esporte no Brasil: do período colonial aos nossos dias. São Paulo: IBRASA, 1996. 
